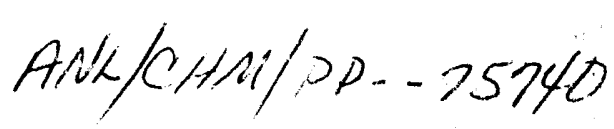

\title{
THE CRYSTALLIZATION OF NEW SYNTHETIC ORGANO-CLAYS
}

\author{
Kathleen A. Carrado \\ $1 . . .211 .34$ \\ Chemistry Division, Argonne National Laboratory

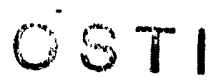

A novel method for the preparation of new synthetic and potentially catalytic clays has been discovered. In this method, a remarkably diverse variety of organic and organometallic molecules can be directly incorporated during the crystallization of the clay. This method has great potential for the incorporation of catalytically active species to create new heterogeneous catalysts. The catalyst precursors are organic-inorganic composites comprised of a layered silicate intercalated with such molecules as porphyrins or metalloporphyrins, organic aromatic dyes, a $\mathrm{Cu}(\mathrm{II})$ phthalocyanine dye, or bulky transition metal chelates. This procedure is readily applicable for introducing specific molecules for highly tailored applications, because successful templates include a variety of catalytically, electrochemically, and photochernically active species. Dr. Kathleen A. Carrado at Argonne National Laboratory carried out the research that led to this discovery and performed numerous characterization studies to establish the composition of the synthetic products, including $X$-ray absorption spectroscopy at the NSLS facility at Brookhaven National Laboratory. The work was supported by the Division of Chemical Sciences, Office of Basic Energy Sciences.

\section{DISCLAIMER}

This report was prepared as an account of work sponsored by an agency of the United States Government. Neither the United States Government nor any agency thereof, nor any of their employees, makes any warranty, express or implied, or assumes any legal liability or responsibility for the accuracy, completeness, or usefulness of any information, apparatus, product, or process disclosed, or represents that its use would not infringe privately owned rights. Reference herein to any specific commercial product, process, or service by trade name, trademark, manufacturer, or otherwise does not necessarily constitute or imply its endorsement, recommendation, or favoring by the United States Government or any agency thereof. The views and opinions of authors expressed herein do not necessarily state or reflect those of the United States Government or any agency thereof. 


\section{THE CRYSTALLIZATION OF NEW SYNTHETIC ORGANO-CLAYS}

\section{Kathleen A. Carrado \\ Chemistry Division, Argonne National Laboratory, 9700 S. Cass Ave., Argonne IL 60439}

The usual method for modifying layered silicate clay minerals is by ion-exchange, where the exchangeable alkali or alkaline earth cation is replaced by another cationic species. Now a new method for incorporating a remarkably diverse variety of organic and organometallic molecules directly during the crystallization of synthetic clays has been developed. This procedure promises to be an easy and readily applicable means for introducing specific molecules for tailored materials applications, because successful templates include a variety of catalytically, electrochemically, and photochemically active species.

The new method involves refluxing a reactive gel of silica sol, magnesium hydroxide sol and lithium fluoride for just two days in the presence of an organic or organometallic intercalant. This results in the formation of crystalline hectorite clays containing either (a) water-soluble porphyrins or metalloporphyrins, (b) organic dye molecules such as ethyl violet (EV) and methyl green (MG), (c) dye molecules such as alcian blue that are based on a $\mathrm{Cu}(\mathrm{II})$ phthalocyanine complex, or (d) transition metal complexes such as Ru(II)phenanthroline and Co(III) sepulchrate. Figure 1 displays structures of these various templates. The following properties of any intercalant are necessary: (i) water-solubility, (ii) positive charge, and (iii) stability under the moderately basic (pH 9-10) aqueous reflux conditions. The materials, and ion-exchanged natural hectorites for comparison, have been exhaustively characterized by several myriad techniques. A few illustrative examples follow.

Bulky Transition Metal Complexes. Metal chelates such as Ru(II)- and Fe(III)phenanthrolines and Co(III) sepulchrate are electrochemically active species which, because they 
are readily adsorbed onto clays, can benefit by the advantages of a heterogeneous support (enhanced efficiency, selectivity and recovery). A typical X-ray powder diffraction (XRD) spectrum of a thin film is shown in Figure $2 a$ for syn. Co(III) sep-hectorite, and Figure $2 b$ displays for comparison the XRD spectrum for a thin film of a natural hectorite ion-exchanged with the cation. In the latter case the material is highly ordered because a (002) reflection is observed in addition to the exceptionally intense (001) reflection at $17.1 \AA$. Orientation information, i.e. how the template is aligned in the clay gallery, can be assigned from these data in a qualitative way. Since the synthetic material has a d(001) spacing at a much lower value of $14.7 \AA$, it is likely that the sepulchrate cage aligns parallel to the clay layers during crystallization. In the ion-exchanged material, the cages are oriented more perpendicular to the layers. This behavior can be related to the cation exchange capacity and surface charge of the clay mineral.

Dyes. The dyes MG and EV display similar orientation phenomena in their XRD spectra as the bulky transition metal cations described above. In addition, EV is known to display metachromasy (UV-visible spectra dependent upon dye concentration) with clays. Very dilute solutions of $\mathrm{EV}$ in water give a $\pi \rightarrow \pi^{\star}$ absorption band with a maximum at $595 \mathrm{~nm}$ (see Figure 3) attributed to monomeric dye molecules. More concentrated solutions display the clear development of another band in the $520-550 \mathrm{~nm}$ range (metachromasy) that is assigned to dimers. The diffuse reflectance (DR) spectrum of a thin film of pure EV contains a broad feature encompassing the entire region of both bands. The DR spectrum of syn. EV-hectorite is similar, with a maximum shifted to $535 \mathrm{~nm}$ to indicate further aggregation of dye molecules.

Porphyrins. Metallation-demetallation properties of tetrakis ( $, N, N$-trimethyl anilinium) porphyrin (TAP) and $\mathrm{Cu}(\mathrm{II})$ TAP-clay systems have been probed in detail by X-ray absorption techniques (XAS), DRS, and XRD. The X-ray absorption near edge spectra (XANES) and fine structure spectra (XAFS) of a CUTAP-exchanged clay are nearly identical to those of a Cu-clay 
exchanged with free base TAP. In addition, they are both very different from a Cu-clay where $\mathrm{Cu}\left(\mathrm{H}_{2} \mathrm{O}\right)_{6}{ }^{2+}$ is the species present, so that CUTAP can confidently be assigned to be the species present in each porphyrin-containing clay. The XANES data are displayed in Figure 4 . These results are in line with those obtained from DRS, and taken together they indicate that Cumetalloporphyrins are exceptionally stable on a clay surface.

Conclusions. The information obtained from the variety of characterization techniques employed provides a comprehensive picture of the individual characteristics of each synthetic material. The organic portion spans an enormous range of possibilities in structure and complexity, which is evident from Figure 1. Precisely because of this diversity in templates, different materials can be prepared with highly specific properties.

\section{Acknowledgement}

This work was performed at Argonne National Laboratory under the auspices of the Office of Basic Energy Sciences, Division of Chemical Sciences, U. S. Department of Energy. XAS spectra were recorded on line $\times 23 A$ at the National Synchrotron Light Source (Brookhaven National Laboratory). 

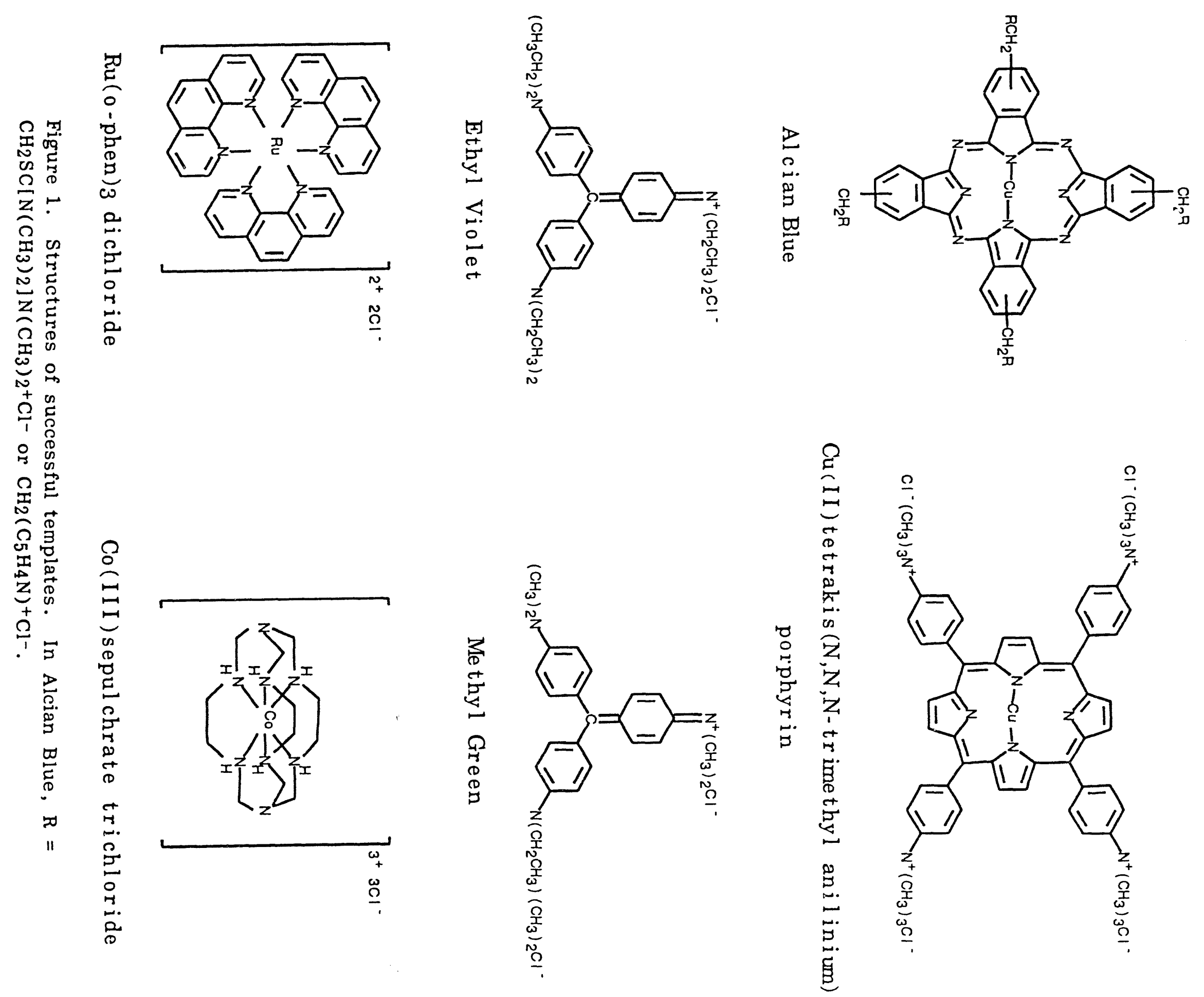
FIgure 2. XRD spectra of Co(III)sepulchrate (a) In synthetlc hectorlte and (b) lon-exchanged In natural hectorite.
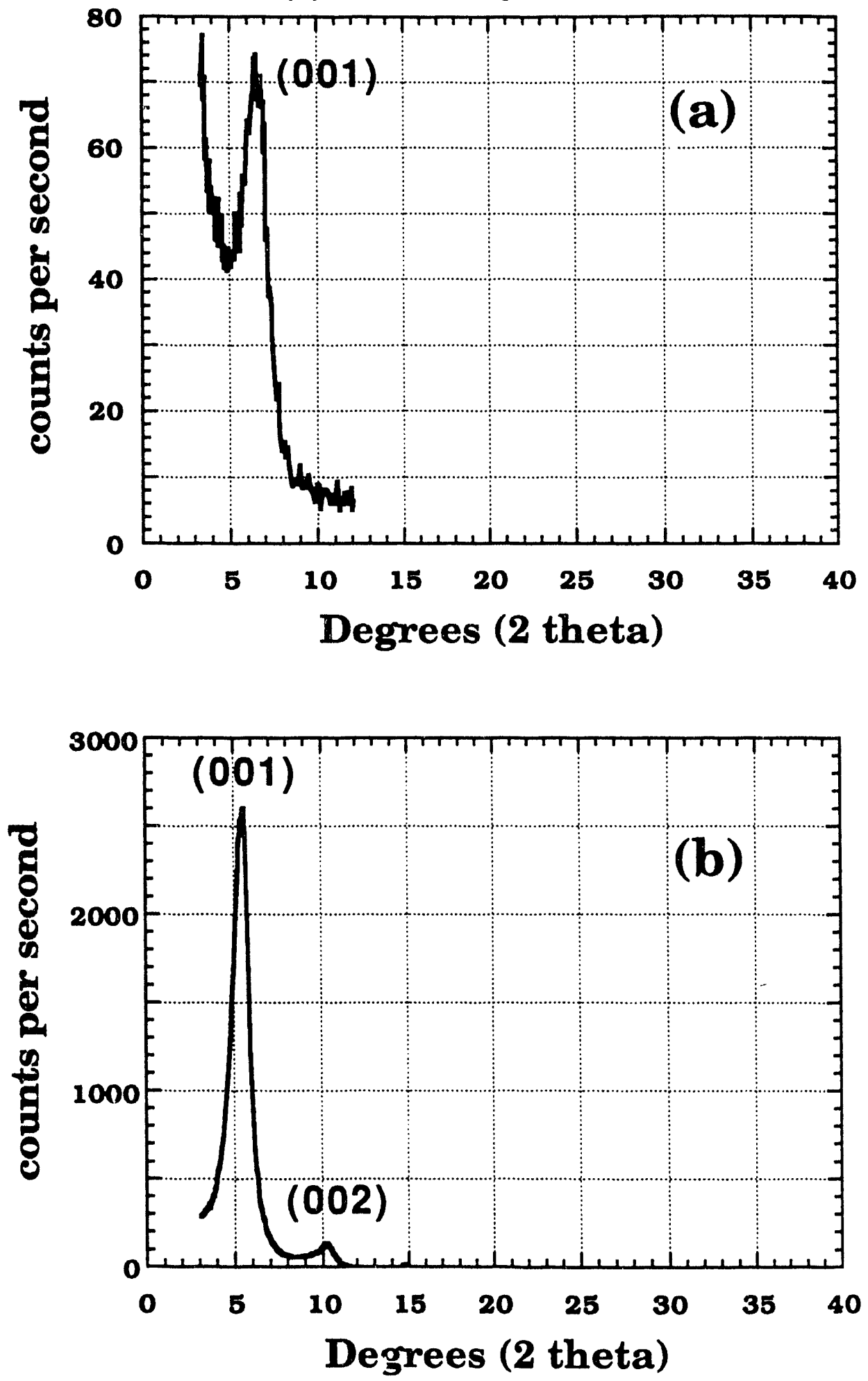
Relative Intensity

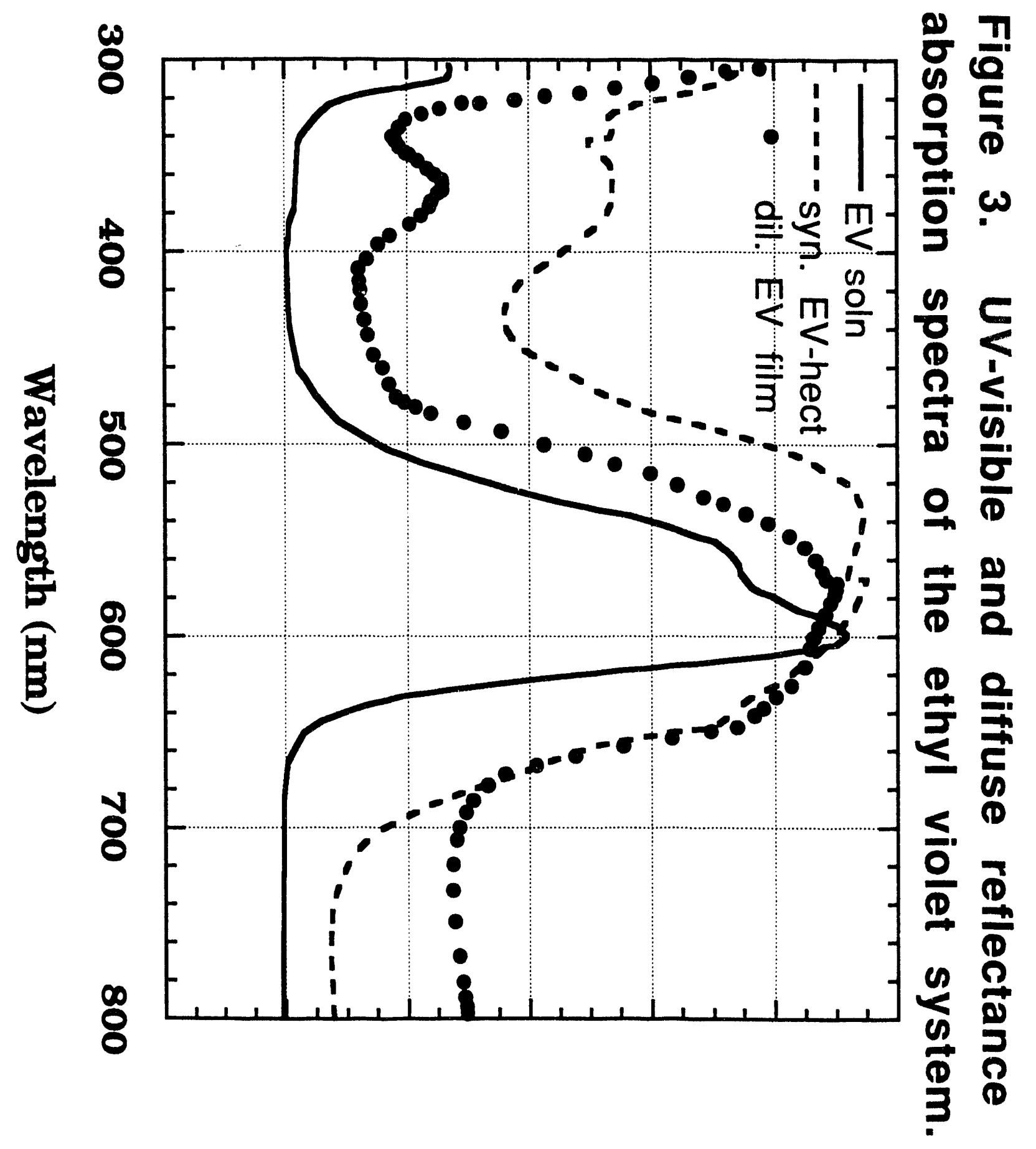


Figure 4. XANES spectra of $\mathrm{Cu}(\mathrm{II})$-containing bentonite clays.

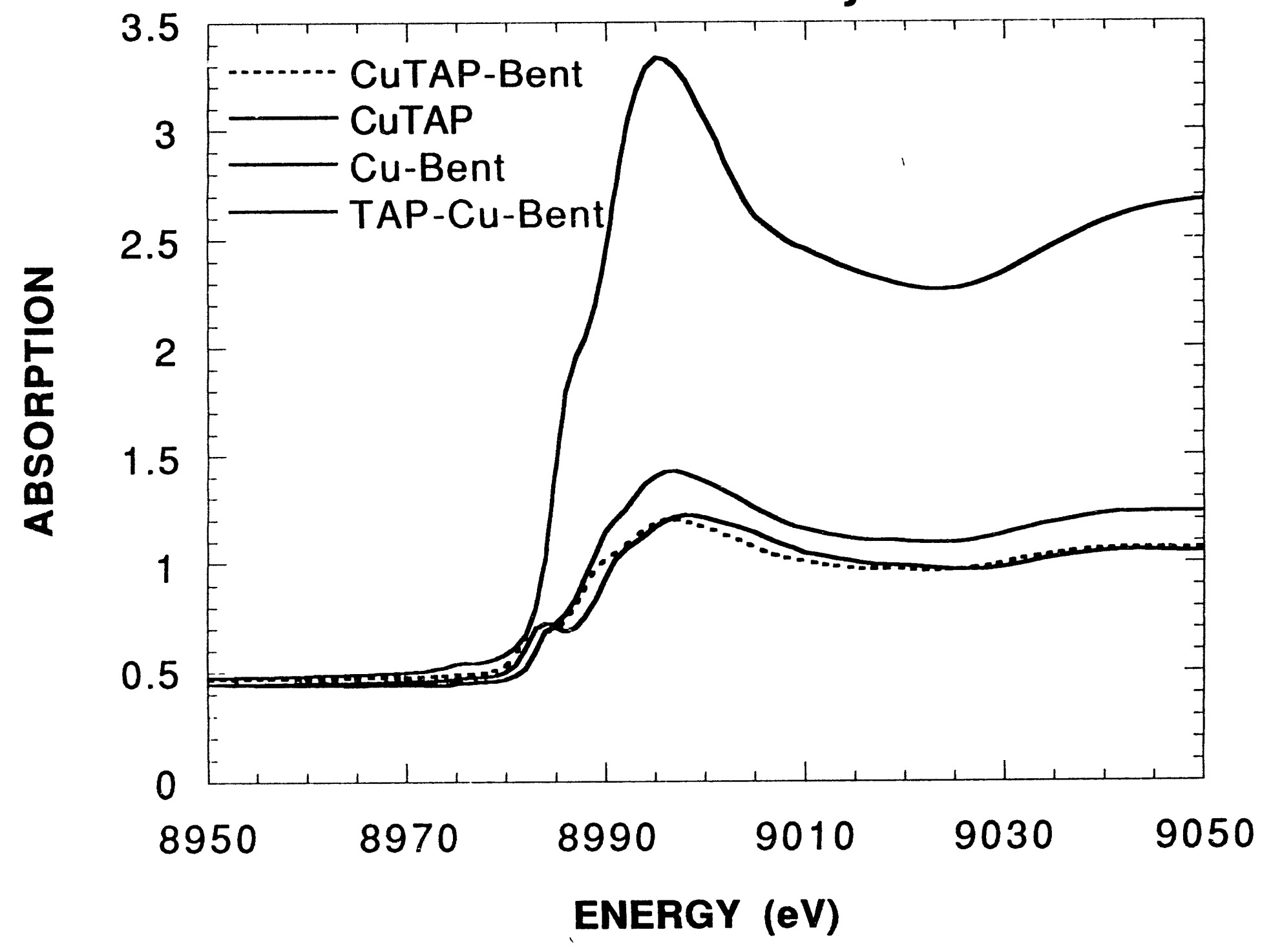




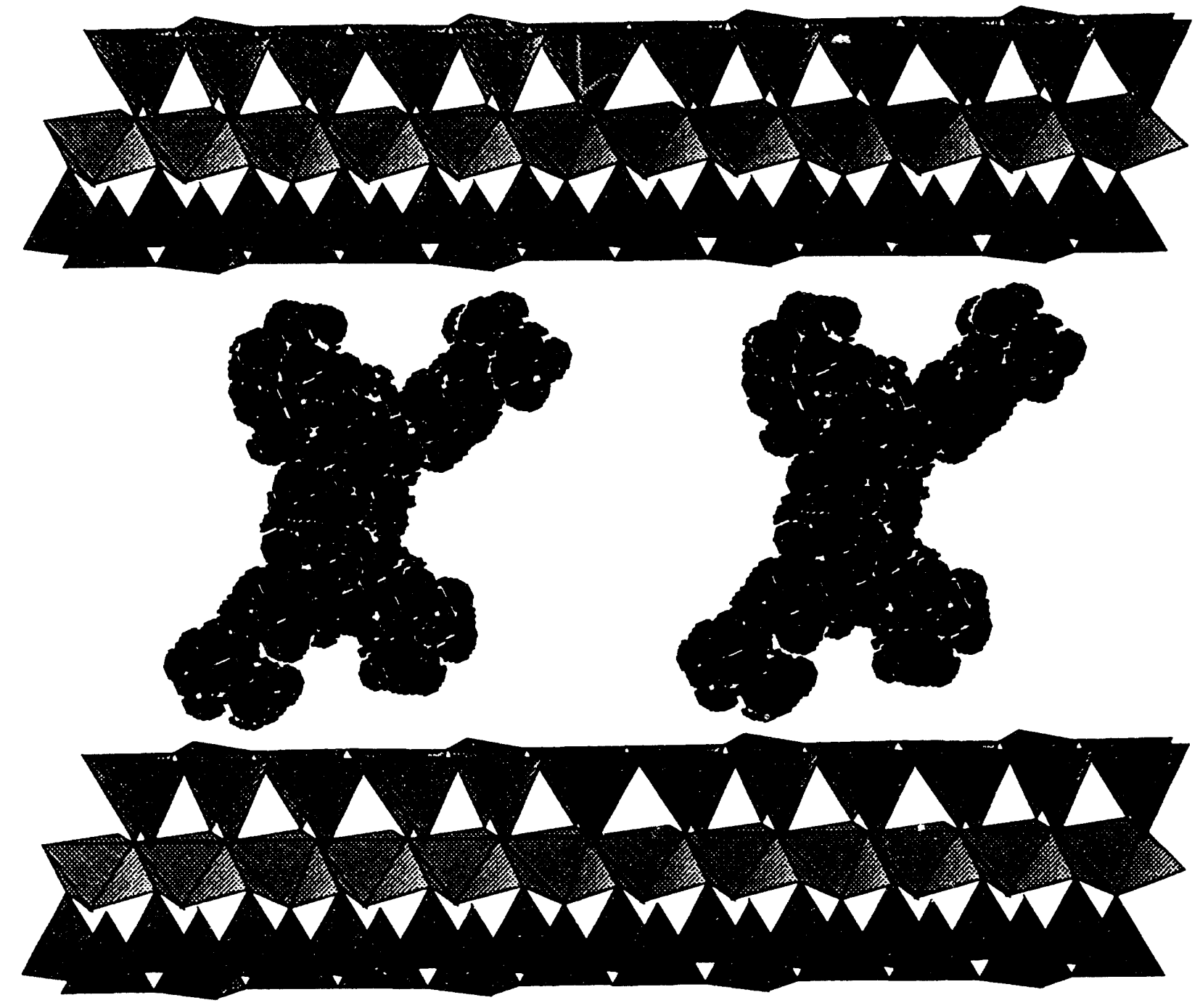

Porphyrin molecules stacked face-to-face in the gallery regicn of a synthetic layered clay. The arrangement continues in all three dimensions. Note the space available between porphyrins for catalytic reaction. (K. A. Carrado, et al., ANL). 

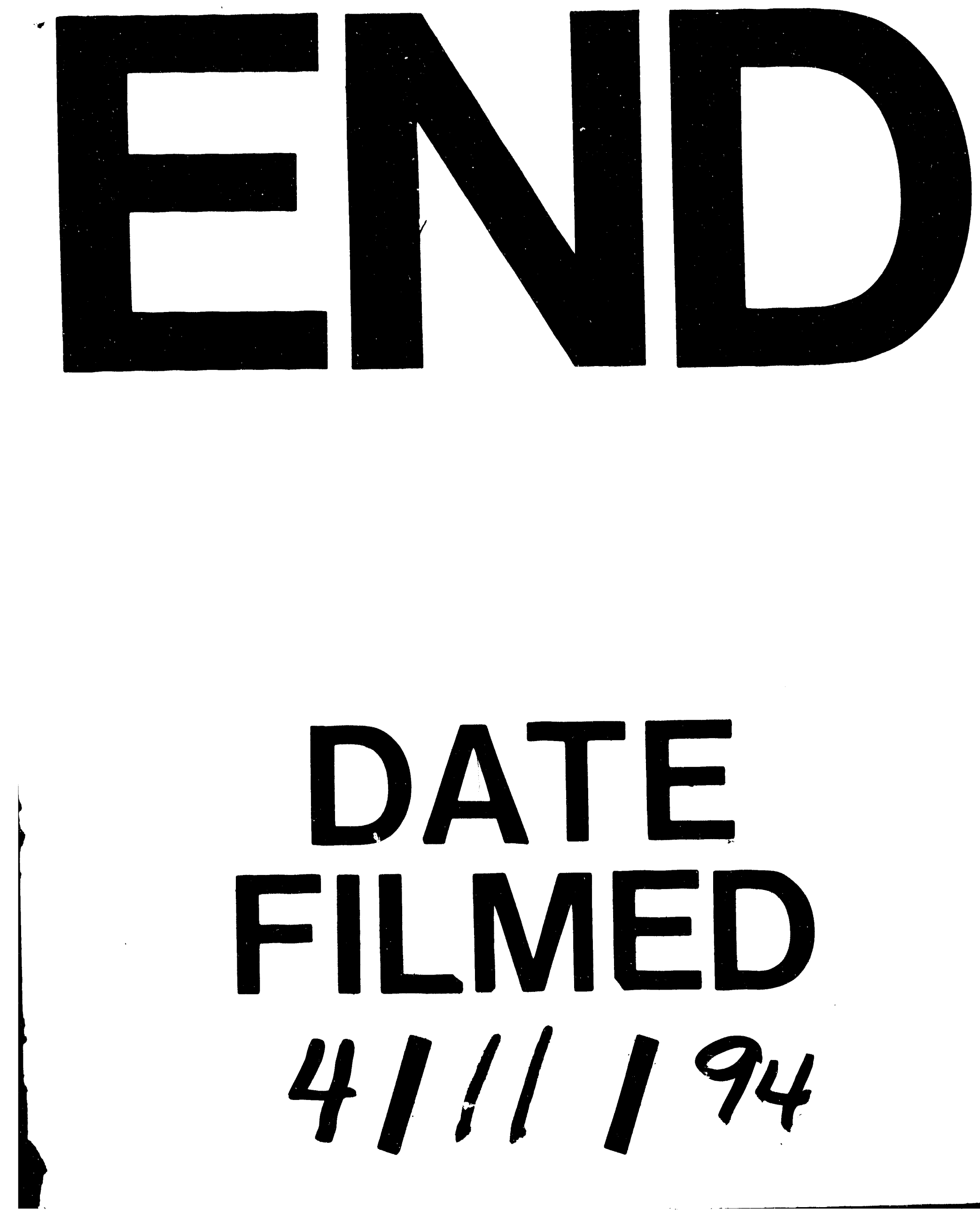
